\title{
Ketoester-Ene Reaction of Silyl Enol Ether to Construct Quaternary Carbons
}

\section{Key words}

ketoester-ene reaction

quaternary carbon

palladium

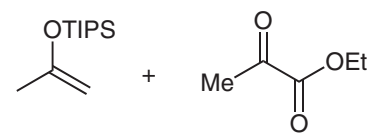
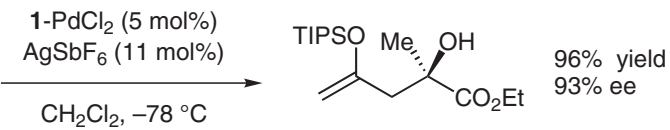<smiles></smiles>

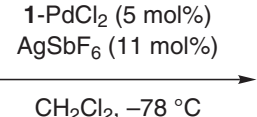<smiles>C=C(CC(O)(C(=O)O[In])C(=O)OCC)C(=O)OCC</smiles><smiles>C=C(C)OCCCCCCCCCC(=O)C(=O)c1ccccc1</smiles>

1- $\mathrm{PdCl}_{2}(5 \mathrm{~mol} \%)$ $\mathrm{AgSbF}_{6}(11 \mathrm{~mol} \%)$
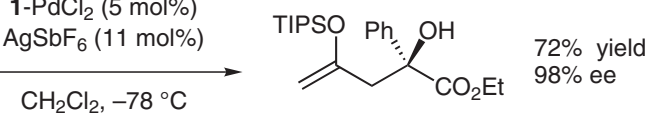

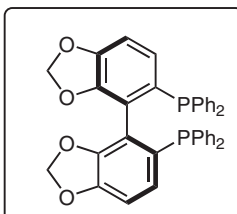

1 (S)-SegPhos
Significance: The authors describe a highly enantioselective ketoester-ene reaction that generates optically active $\beta$-hydroxy silyl enol ethers containing tertiary alcohols. This is a very nice reaction because the product not only contains a chiral quaternary carbon, but also a useful silyl enol ether. A reasonable amount of $\alpha$-ketoester substrates works well with this reaction. A SegPhos-Pd-Ag catalyst system is used with the silver's likely role to generate the cationic palladium species.
Comment: This is a fantastic report for the construction of a very useful compound. The study of silyl enol ether starting materials revealed that the TMS enol ether gave only Mukaiyama-aldol-type products. Using TBS resulted in good yield and moderate enantiomeric excess (85\%). TIPS and TBDPS gave high ee values (93\% and 96\%, respectively), but with TIPS much higher yields were achieved (96\% vs 68\%). The authors showed an example of lowering the catalyst loading to 0.01 mol\% without serious decrease in ee or yield. 